DOI: $10.7596 /$ taksad.v2i4.299

\title{
Perceptions of Cultural Differences between Turkish and German Societies: Personal Observations of two German Erasmus Students at Karabük University
}

\author{
Marie Louise Neumann* - Sarah-Lena Knust**
}

\section{German Society}

To define a certain mentality, way of life respectively, as the distinct culture of a certain nation, is impossible. As scholars know, both the notions of 'culture' and 'nation' have been socially constructed and their definitions are highly disputed. Furthermore, the current concept of transculturality replaced the formerly predominant perception of culture introduced by theorist Johann Gottfried Herder in the $19^{\text {th }}$ century (Welsch 2000).

Many factors determine one's culture. The social background essentially shapes the mentality of oneself. At the same time, personal experiences also heavily influence one's way of life. Therefore, a 'working-class man' probably has a different culture than a well-educated wealthy woman. Besides, the historical development of a country contributed to what might be declared as the characteristics of a culture typical for this particular nation.

In the last years, the increase in social disparities in Germany has become such an alarming trend that the media often speak of parallel societies. Consequently, one can assume that there is a wide range of distinct cultures, ways of life respectively, present in Germany. Thus, we would like

\footnotetext{
* University of Mannheim, Student of English Department.

** University of Mannheim, Student of English Department.
} 
to clarify that by speaking of 'German culture' we are not talking about a distinctive lifestyle that can exclusively be ascribed to German people, but rather about mentalities and forms of behaviour that are, on the one hand, incorporated by the majority of the Germans we are acquainted with and that, on the other hand, are regarded as typically German according to the public opinion. All in all, we want to emphasize this aspect, because we do not want our personal view on German culture(s) to be regarded as representative for the lifestyle of all German citizens.

\section{Dominant culture}

The term 'dominant culture' suggests that this form of culture oppresses and marginalises other forms. Thus, one might argue that the term is problematic, as it directly evokes the impression of ruling over something else and, as a logical premise, being aggressive. This connotation is rather negative. Notwithstanding, one could discuss whether the term 'dominant culture' really is misleading or whether it simply describes reality. Whoever does not fit into the norm, is generally regarded as strange and as a social outcast. Consequently, people with differentiating forms of behaviour and mind-sets are pushed to the periphery of society and away from the centre, which means that they are also pushed away from power, since being in the centre means being with the masses, i.e. being the norm, which means one is in control. To avoid further discussions on this term, we will replace it by 'mainstream culture' in the following. Hence what does German mainstream culture look like? Although we are German, the question is not easy to answer for us. In general, we have the impression that it is easier to define typical features of a culture from the outside perspective, i.e. if one does not belong to it. Anyway, Germany is culturally divided into many different regions. People who live close to the seaside are usually known as being friendly and relaxed, people in the west as being very economically orientated, always aiming to be successful in their career, while people from the east of Germany are often presented as being a bit backwards-oriented, while people from Bavaria seem to form a whole different culture for themselves, very traditional and probably are a living stereotype of how many foreigners imagine Germans to be. As Edward T. Hall's Cultural Iceberg Model visualises, only few components of culture are displayed overtly. Among these are e.g. folkloric dances, local dishes and clothing. The biggest part, however, remains invisible and cannot be detected that easily. In the following, we will describe the more obvious aspects of German mainstream culture.

Many people from other countries believe that German people wear leather-pants, eat sausages and drink beer all the time. These attributes, however, are merely stereotypes, rooted in customs specific to certain regions of Germany. Leather-pants, for example, are traditional clothes only worn in Bavaria and in some parts of Baden-Württemberg, i.e. in the South of Germany. 
Eating sausages, however, especially Bratwurst, is common all over Germany and is regarded as normal and nothing extraordinary. As a German, one would barely take notice that the notion of eating sausages is typical German, while foreigners often point out that this particular notion is a feature of German culture. In spite of that, one has to emphasize that not every German eats sausages. The same is true for drinking beer. Many Germans are fond of drinking beer and many regions have their own local beer. Beer really shapes our social interactions in terms of that many Germans above the age of 18 meet with friends in a bar during the week to have a glass or two together and just talk. Notwithstanding, not every German like beer, and in some regions, as e.g. in Rhineland-Palatinate, wine plays a bigger role in society than beer. Furthermore, beer is not only a big component of German drinking culture, but also e.g. of the Belgian and Czech ones. Thus, one cannot exclusively ascribe the importance of beer to German culture. More important than these often considered overt aspects of culture are the ones that are lying under its surface. The attempt to understand another culture can only be successful, if one 'digs deeper' into the mentality of the people belonging to that particular one. One characteristic trait Germans are well-known for is their 'obsession' with detailed planning and organisation. In accordance with that is the high value of punctuality. One has to admit that this cliché is definitely true for the German majority, at least for the ones belonging to the mainstream culture. Arriving too late to a meeting, no matter whether it is has an official character or is just with some friends, is regarded as impolite. Even if a German does not consider him- or herself as a well-organised person, he or she might recognise during a stay abroad in a culture with a different mentality concerning this point that organised plans and timetables do matter to him or her.

Another aspect is the straightforwardness in communication. Most Germans express clearly and directly what they want, without using pleasantries. People who are not accustomed to that form of communication might consider Germans impolite or even rude. For Germans, however, being straightforward is desirable. The direct expression of thoughts, wishes and plans fits to the aspect of organisation. It saves time and is more efficient. Plus, misunderstandings that might occur due to an indirect way of communication are avoided, which is an advantage in the process of planning something.

Another feature needed for good organisation is efficiency. Germans highly value wellstructured plans without redundant extras. The more efficient something is organised, the more time or money is left to be invested into something else. Efficiency also plays a big role in worklife. Workflows are optimised to the utmost so that the workforce of a single person can be used as efficiently as possible. 
This notion leads us to our next point. Work plays an important role in the German mainstream society. Germans are proud of their good international reputation in the fields of industry and technological innovations and especially of the fact that the branding Made in Germany is regarded as a sign for good quality worldwide. One of the reasons for this reputation might be that Germans often identify themselves with their profession - working is part of their identities. As a consequence, unemployed people living from social welfare are often marginalised in the mainstream society.

Another important factor of many cultures is family life. In Germany, this whole notion is highly debated. The traditional patriarchal system is still present in mainstream society. Men concentrate on their careers, and also there are programmes supporting men who take a break from work and stay at home to take care of their children, only the minority of fathers uses this possibility. By contrast, working women are often facing obstacles when they try to combine career and children. Several programmes are initiated to change that situation, e.g. by guaranteeing places in a day nursery for all children, yet progress is slow. One can state that the status of family is undergoing changes in Germany and is a much-discussed topic.

Having introduced political topics, we would like to continue with the notion of patriotism. As we know from our parents' generation, in the past, Germany and Germans were perceived very negatively in other countries. Our generation, however, seems to experience a shift from a negative to a highly positive image of Germans, as we experienced that many people abroad consider Germans as open-minded and friendly people. In general, praising Germany is observed with suspicion; of course because of the German past. Emotional attachments to the German nation are therefore not displayed overtly. Apart from the pride of the reputation of German economy, the only occurrence to celebrate Germany is when sport events take place. The most important event for Germans is here the World Football Championship, when everything is decorated with the colours of our flag and people assemble to watch the football matches together. Football generally plays a big role in German mainstream culture and is the most popular sport in the country. The success of both the male and female national teams strengthens its status and awakes strong emotions in their supporters. A stereotype about German people is that they are very rational and act cold. In our opinion, this cliché is not true, although there are regional differences in the mentalities of German people.

Another aspect we would like to mention is the influence of Christianity on our culture. In Germany, religious freedom is guaranteed. However, our Grundgesetz (the substitute of a constitution) is based on Christian norms and directly mentions the Christian God in the preamble. 
Although many people do not feel any attachment to the Church and a great deal of Germans is atheists, it is undeniable that some characteristics of Christianity are still influential. On the $3^{\text {rd }}$ of October 2010, the former German federal president Christian Wulff declared in his speech to the $20^{\text {th }}$ anniversary of the German Reunification that the Islam belongs to Germany. This statement provoked not only a new debate on how to deal with immigrants and integration, but also on what constitutes German culture. This discussion shows that many Germans embodying the mainstream culture favour its Christian roots have problems with recognising other ways of life in Germany, as e.g. practised by people with emigrational background, as an equal culture. They see themselves as the norm, although Germany has become a destination for many emigrants and cultural diversity is commonly accepted in public. This ambivalence demonstrates that the German mainstream culture struggles with identity questions.

\section{People with Turkish migration background in Germany}

In the 1960s, the German and the Turkish government signed a recruitment agreement which allowed Turkish people to come to Germany to work as so-called Gastarbeiter, because Germany was in need of cheap labour force. However, the German government did not consider the option that the Turkish immigrants might want to stay in Germany. As a consequence, integration policies were initiated very late and failed. The Turkish community kept to oneself and a parallel society started to exist. Over the last decades, the German citizens of Turkish origins, the so-called 'German Turks' became more and more accepted by the German mainstream culture. German Turks are now present in all regions of Germany, both in rural and urban areas and are not regarded as alien anymore. Turkish restaurants are very popular among German people of all age and seem to be most visible contribution to Germany or maybe even German culture. In addition, mosques have been built especially in bigger German cities. However, some prejudices are still maintained and not all problems are solved. On the one hand, especially in big cities, the Turkish parallel society remains intact. Many relatives that joined their already in Germany living brother, husband, son etc. came to Germany with lacking knowledge of the German language. This is a big problem, as that means that many people with Turkish migration background preferably stick to their own community, because they lack the skills to communicate with German-speaking people. In many cases, children of Turkish origin entering kinder garden or school hardly speak or understand German. However, many programmes have been initiated to improve the situation. Notwithstanding that, many Germans have the prejudice that those German Turks take advantage of the social welfare system in Germany, since many of them cannot speak German and consequently cannot work in every job. In urban areas, the large Turkish communities, which often inhabit big districts

of their own with Turkish signs in their shops, often evoke the impression that they are not willing 
to integrate. Instead of recognising the difficulty to adapt to a new culture without losing one's own origin and demonstrating solidarity and the wish to communicate with each other on the same level, many Germans think men of Turkish origin are macho-like and oppress the women they are acquainted with. A common belief is that Turkish people are disrespectful to women, that they force their female family members into a patriarchal belief in which they only have to obey their male family members and have no rights of their own. Several cases in which male German Turks murdered a female relative who became westernised supported the impression that German Turks do not want to integrate and that male German Turks are very aggressive.

On the other side, however, many German citizens with Turkish migration background adapted the German mainstream culture and try very hard to be regarded as equal. Many of them are successful in their job position and have a high living standard. Nevertheless, statistics prove that those people still face obstacles while pursuing their career. For example, the number of German Turks entering into higher education facilities is still very low in comparison to Germans without immigration background. This current state of affairs has to be changed as soon as possible. The failure of politics to improve this situation needs greater public attention to put the government under pressure. Yet it would be wrong to believe that the German-Turkish relationship in Germany is all negative. We do not really know how to describe our relationship, since it is a strange mix of the acceptance of cultural differences, assimilation and separation.

In our opinion, now that we have lived in Turkey for a few weeks, it is impossible to define the original Turkish culture by spending time with German Turks; since so many intercultural interactions took place that their children, also known as my generation and the following, are somehow hybrids, somehow forming their own culture, somehow belonging to both nations, but yet differing from German or Turkish culture in many ways. We, as Germans have also friends of Turkish origin in Germany. Because of that, we have been aware of the prejudices existing. One cliché, however, is definitely true in our opinion - Turkish people are very sociable and hospitable and value family more than many Germans do.

One of the reasons why we chose to do our Erasmus semester in Turkey was that we wanted to experience Turkish culture and to check ourselves if all those negative accusations are there for a meaning or not. Now that we have been in Turkey for several weeks already, we can only say that "real" Turkish people differ a lot from the Turkish stereotype created in Germany.

\section{Observations of Turkish Culture}

The above mentioned positive expectations were more than fulfilled. We never thought that 
people could be so friendly, sociable and warm as the Turkish ones we met here. We are very glad that we have had the chance to make this experience. Our Turkish friends in Karabük try to make our stay as great as possible, they help us to organise our trips and take us to places and sights worth seeing. In addition, they took care for the administrational affairs we had to undergo. For example, on our first day we went through a lot of trouble. However, immediately students on campus asked us if they could help us and do anything for us. When we told them about our problems, they called people who could help us. One of the students actually waited with us for two hours until the professor we had to see had office hours, came with us to meet him in case he was needed as a translator and also drove with us to the police station to get our residence permit. This is something no one in Germany would do for strangers. Germans would have told us where to go and from then on it would have been our problem. Also so many students we met invited us to have dinner with them and offered us to help us finding a flat. Plus, they introduced us to their friends, even though many of them are not proficient in English. This is one point we did not expect - that even the majority of students in Karabük is not able to communicate in English. We understand, however, that the methods to teach English in Turkish schools lack speaking practice and since Karabük is no touristic area, English is not needed in everyday life or business. We appreciate, however, that many Turkish students say themselves that they would like to improve their English and take the chance to practise with us exchange students. By contrast, in touristic regions everybody seems to speak English; yet, we had the feeling that people in those regions only talked to us, because they were interested in our money. Their expressions missed the welcoming appearance we were used to from people in Karabük.

Young Turkish males are nothing like the Turkish youngsters in Germany. Our male friends are very polite, very helpful and we never experienced that anyone of them was disrespectful towards us or other girls. They cooked for us several times, gave up their seats in the bus to us and the like. Our female friends are also different from what we expected. We thought that most of them would wear a headscarf and that many Turkish girls and women would not like us and consider us as unmoral Western people they do not want to be in contact with. The opposite was the case.

There are four features we are still trying to become accustomed to. First, there is the indirect communication. As every Turkish person tries to be as nice and polite as possible, they often use pleasantries and do not give direct orders. Even if you just ask for a time to meet, you will rather get the answer "whenever you like" instead of a direct time. Although this is of course meant to be positive, it is hard for us, because we need clear answers to our questions for our selforganisation and self-management. For example, when we talk to a (Turkish) friend on campus and we want to meet, we always ask: "Sounds great, when shall we meet?"; and he or she replies: 
"Tomorrow". At first we were very confused, because in Germany, first of all, one would not meet the next day, because there is not enough time to plan in advance. It would at least be the day after tomorrow. Also one would immediately give a time as well, as for example: "Tomorrow at 11 o'clock?". So, in our confusion we used to ask: "Ok, when tomorrow?" and almost always got the answer: "Sometime tomorrow, we'll see".

This is something which no one would ever say in Germany, so we always became a little nervous and did not know how to react. By now, we know that we can just relax, because our friend will call us some time later on the same or the next day and will say something like: "Hey, I thought about our meeting, let's have dinner at seven/tonight?" and everything will be fine. Now we really like this spontaneous way of dealing with things in the social sphere and we really think that if Germans would adopt this, we would be a lot less stressed and more relaxed. As we pointed out before, Germans are mostly well-organized; this also is true for our bureaucratic sector. In our university we have many people working on different fields in the Erasmus office. They work in a well-structured way and can give the Erasmus students coming to Mannheim detailed information on their stay and courses. In Turkey, we faced some problems according our accommodation and courses, since there was no direct link between the Erasmus office and the staff in charge for the courses and the owners of the dormitories.

The second issue is about paying bills. In Germany, everyone pays for his or her own, at least in our age. Here, we are always invited by our Turkish friends, who make us sometimes feel uncomfortable; because we know that they are also students and probably will not have that much money either. We were explained, however, that this is Turkish culture - paying for one's friends coming to your hometown, and those men always pay for women. In general, we were aware of the fact that the patriarchal system is still even more dominant than in Germany, recognisable for example in the number of women working in public places, such as restaurants and busses. In a discussion about female car drivers, some male Turkish friends said that they are not sure whether they support women driving or not. Notwithstanding, as emancipated women - who were lectured in Gender Studies as well - we disapprove the custom of men paying for women.

Still we know that this is a part of Turkish culture we have to accept and we are trying to do so.The third aspect is that Turkish people smoke very much. This can be seen as a social custom and a replacement for drinking alcohol, and of course it is a matter of discussion whether smoking or drinking alcohol is more harmful, but still we must say that we are very glad that smoking becomes increasingly disapproved in Germany. The last notion deals with the conservativeness in dormitories. Our dormitory is owned by a landlady who insists that we do not drink alcohol, do not 
bring male friends to our rooms and are home before midnight. This is something which cannot be found in Germany. Students in dorms are treated as flat-owners, which means that they can do there whatever they like. Never would there be an adult watching them, since they are considered as grown-ups who are responsible for themselves and can make their own decisions.

Another interesting observation we made is the role religion plays for Turkish youth. In general, religion seems to play a bigger role in Turkey than in Germany. Many people regularly visit the mosque and do neither drink alcohol nor eat pork. Religious women can be easily recognised as they wear headscarves. However, the calls of the muezzin do - in my opinion - not represent a bigger influence of the Islam in Turkey than Christianity in Germany, since they have the same functions as church bells in Germany, which also ring several times a time and to which one also has to listen if one is not religious. To us it was a new experience to see how well Turkish students practising their religion and those who do not get along with each other. It is not a matter of discussion, but a given circumstance. In Germany, young people practising their Christian religion are often marginalised by other adolescents or young adults, who feel that being atheist is a sign of more intelligence and rationality, maybe of superiority if one wants to use that term. For Turkish students, however, the intermingling of religious and non-religious students is normal.

What seems to be an expression of the warm-heartedness of Turkish culture is the way how people greet each other. In Turkey, one mostly kisses other people on the cheeks or gives them a warm hug. This is not very common in Germany, where you either shake hands or hug your acquaintance, depending on how close your relationship is. Another sign of sociability is an invitation to eat together. The Turkish cuisine offers a wide range of diverse meals, and we were told about this Turkish saying: If you see people eat, join them. If you see people fight, escape them. This underlines the big role eating plays as a social event in Turkey, which is different to Germany, where the role of eating is due to the focus on other tasks mostly reduced to a means to survive. Only sometimes, if one has enough time, cooking eating is celebrated as a get-together by friends. One point is that we are not sure whether or not it is rooted in Islam traditions or simply Turkish culture in general, is hygiene. While taking off the shoes before entering a house or flat clearly stems from Islamic culture, we were surprised about the hygienic towels and the liquids of which we do not know whether they are soap or crème that are offered after meals or bathroom visits. Nonetheless, we like this custom, because to us it looks like they care for their fellows. Immigration does not seem to be very common in Karabük, at least not from Western countries. In such, we - as blond women - had to get used to getting stared at while walking through the city or at the campus. Some people come and ask as what we are doing here - if they know English - others simply do not try to hide their gaze. In Germany, people are used to immigrants and to seeing 
people with different skin or hair colours, and if there was something extraordinary worth to be stared at, people would try to stare as discretely as possible. This is different in Turkey, and we, Erasmus students, had to learn to cope with this situation. However, we observed that this situation is different in big cosmopolitan cities such as Istanbul and is only due to the fact that Karabük is a rather small and non-touristic city. The feature of Turkish culture we like most is the fact that everyone seems to enjoy dancing and listening to Turkish music. Even though German songs are very popular in Germany as well, American and English music dominates in our country. In Turkey, we rarely hear English songs. We consider this as an important way to preserve the Turkish culture. And the fact that also Turkish men dance to folkloric music makes us very happy, because in Germany dancing is considered as a rather female activity in the opinion of many men.

Turkish people seem to be very proud of their culture, which we can understand since it is a huge country with an influential and diverse history. They are very patriotic - Turkish flags decorate the landscape and a painting of Atatürk is present in every room. We really appreciate this and we wish Germans would show more affection towards their own culture.

\section{Conclusion}

German and Turkish mainstream cultures seem to differ a lot. However, instead of considering these differences as something bad which separates us, we should embrace this difference as something which makes our relationship interesting and encourages us to learn from each other. Nowadays, both countries are undergoing processes of globalisation and become more similar. Thanks to the concept of transculturality, we hope that one day nobody will try to distinguish between clear-cut cultures anymore, but that the notion that we are just all humans becomes widely accepted. We should try to meet each other free from prejudices about our nationalities. Still we have to say that we have only been living here for a couple of weeks and we are looking forward to learning more about Turkish culture and observing cultural differences so that we can inform other Germans having prejudices at home about how reality looks like.

\section{Bibliography}

Welsch, Wolfgang (2000). "Transculturality - the Puzzling Form of Cultures Today“. Spaces of Culture: City, Nation, World, ed. by Mike Featherstone and Scott Lash, London: Sage 1999, 194213. 